\title{
Design and baseline characteristics of the ParkFit study, a randomized controlled trial evaluating the effectiveness of a multifaceted behavioral program to increase physical activity in Parkinson patients
}

Marlies van Nimwegen ${ }^{1}$, Arlène D Speelman ${ }^{1}$, Katrijn Smulders ${ }^{2,3,4}$, Sebastiaan Overeem², George F Borm ${ }^{5}$, Frank JG Backx ${ }^{6}$, Bastiaan R Bloem², Marten Munneke ${ }^{1,3,7^{*}}$, ParkFit study group ${ }^{1}$

\begin{abstract}
Background: Many patients with Parkinson's disease (PD) lead a sedentary lifestyle. Promotion of physical activities may beneficially affect the clinical presentation of PD, and perhaps even modify the course of PD. However, because of physical and cognitive impairments, patients with PD require specific support to increase their level of physical activity.

Methods: We developed the ParkFit Program: a PD-specific and multifaceted behavioral program to promote physical activity. The emphasis is on creating a behavioral change, using a combination of accepted behavioral motivation techniques. In addition, we designed a multicentre randomized clinical trial to investigate whether this ParkFit Program increases physical activity levels over two years in sedentary PD patients. We intended to include 700 sedentary patients. Primary endpoint is the time spent on physical activities per week, which will be measured every six months using an interview-based 7-day recall.
\end{abstract}

Results: In total 3453 PD patients were invited to participate. Ultimately, 586 patients - with a mean (SD) age of 64.1 (7.6) years and disease duration of 5.3 (4.5) years - entered the study. Study participants were younger, had a shorter disease duration and were less sedentary compared with eligible PD patients not willing to participate.

Discussion: The ParkFit trial is expected to yield important new evidence about behavioral interventions to promote physical activity in sedentary patients with PD. The results of the trial are expected in 2012.

Trial registration: http://clinicaltrials.gov (nr NCT00748488).

\section{Background}

Parkinson's disease (PD) is a progressive neurological disorder characterized by both motor symptoms (such as bradykinesia and postural instability) and non-motor symptoms (such as depression and cognitive impairment)[1]. Both motor and non-motor symptoms can result in reduced physical activity[2,3].

\footnotetext{
* Correspondence: M.Munneke@neuro.umcn.nl

'Radboud University Nijmegen Medical Centre (RUNMC); Nijmegen Centre for Evidence Based Practice (NCEBP), Department of Neurology, Nijmegen, The Netherlands

Full list of author information is available at the end of the article
}

Observations in non-parkinsonian populations suggest that participating in regular physical activity has preventive effects (e.g. cardiovascular events, diabetes mellitus, dementia)[4-6] and positive symptomatic effects (on depression[7], sleep disturbances[8], health-related quality of life)[9]. Studies in PD patients concluded that brief physical therapy interventions can improve flexibility, balance and muscle strength[10,11]. In addition, preclinical evidence in animals with experimental parkinsonism raised the possibility that physical activity may directly alter the neurodegenerative process[12,13]. 
A critical question remains how PD patients can be stimulated best to achieve an enduring increase in their physical activities in daily life, in order to prevent comorbid complications and to improve symptoms.

Simply informing subjects about the health benefits of physical activity is not enough to attain a sustained behavioral change. The challenges to induce a lasting change in exercise behavior are particularly great for neurological patients. To change lifestyle, behavioral programs should focus on appropriate supervision, social support from spouses and caregivers, and the individual's preferences and needs[14-16]. Achieving an enduring behavioral change also calls for specific strategies such as goal setting, problem-solving techniques and motivational interviewing[14,16,17]. Physical activity promoting programs including such elements were effective in sedentary people[15], patients with chronic heart failure[16], and patients with COPD[18].

Stimulated by these observations, we developed the ParkFit program: a multifaceted intervention to promote physical activity in sedentary patients with PD. In addition, we developed the ParkFit trial to investigate whether this program affords increased physical activity levels that persist for two years. The trial will also search for possible health benefits and risks of increased physical activity. Here, we describe the study design and baseline characteristics of this ParkFit trial.

\section{Methods}

\section{Study Design}

The ParkFit trial is a multicentre, randomized controlled trial comparing two arms: physical therapy with specific emphasis on promoting a physically active lifestyle (ParkFit Program); and matched physical therapy with specific emphasis on safety and quality of performing daily activities (ParkSafe Program) (Figure 1). Trial duration is two years. Full ethical approval has been granted for the study (CMO Regio Arnhem-Nijmegen). The study is registered at clinicaltrials.gov (nr NCT00748488).

\section{Patients}

We started with all patients who visited their neurologist in 2007, 2008 or 2009 in 32 participating community hospitals. Eligibility criteria were: (a) PD, according to the UK Brain Bank Criteria[19]; (b) age between 40 and 75 years; (c) sedentary lifestyle defined as: $<3$ times a week vigorous-intensity physical activity for $<60$ minutes; or < 3 times a week moderate-intensity physical activity for $<150$ minutes);[20] (d) Hoehn and Yahr $\leq 3$. Exclusion criteria were: (a) unclear diagnosis (no gratifying and sustained response to dopaminergic therapy); (b) MMSE < 24); (c) unable to complete Dutch questionnaires; (d) severe co-morbidity interfering with daily functioning; (e) daily institutionalized care; and (f) deep

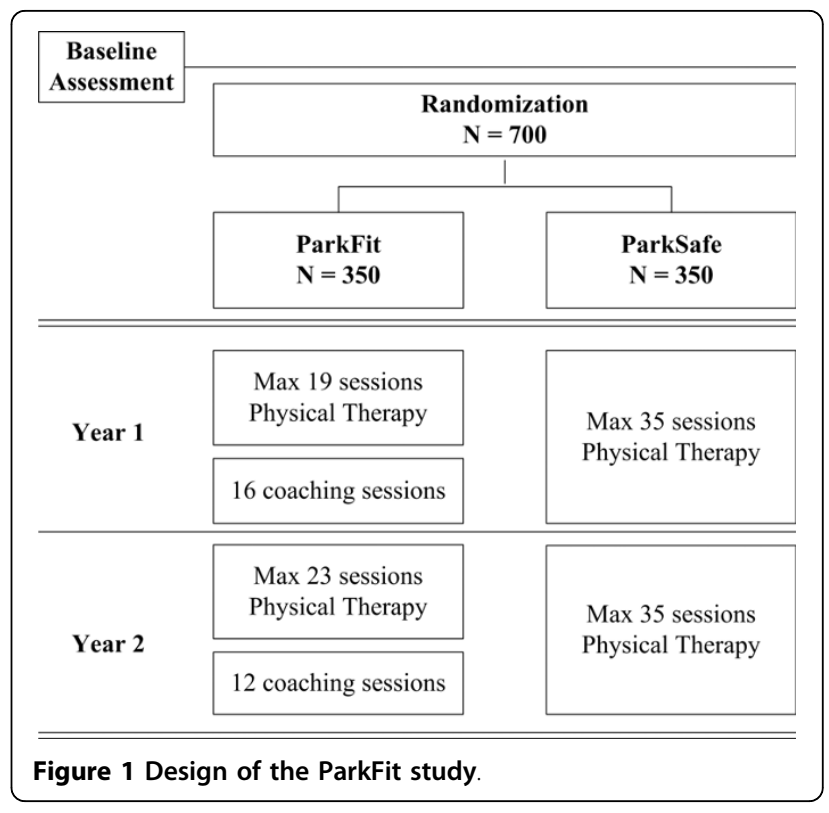

brain surgery. Informed consent was obtained before the first assessment.

\section{The Intervention}

After baseline assessment, patients were randomly assigned to the ParkFit or ParkSafe Program. In both groups, patients receive high quality physical therapy: both interventions are delivered exclusively by experienced therapists who participate in the Dutch ParkinsonNet $[21,22]$. Patients in both treatment arms are offered an equal maximum number of treatment sessions (i.e. 35 sessions of 30 minutes a year; Table 1). Therapists contact patients at least every six months to investigate if there are new aims.

\section{ParkFit Program}

Widely used behavioral change techniques, with demonstrated effectiveness $[16,18]$ and based on models of behavioral change[14,17], are combined in the ParkFit Program to stimulate patients to increase their physical activity levels.

1) Brochure ParkFit Patients receive a brochure covering specific strategies to promote a behavioral change. These strategies include: education about the benefits of physical activity, advice about suitable activities, identifying and overcoming any perceived barriers to engage in physical activity, setting goals, and recruiting social support $[14,23,24]$. Part of the educational workbook is a health contract: a written agreement signed by the patient and physiotherapist to support them in initiating and maintaining physical activities[25]. A logbook monitors the specific goals.

2) Personal Activity Coach Physical therapists serve as personal activity coaches who guide patients towards a 
Table 1 The ParkFit and the ParkSafe program

\begin{tabular}{|c|c|c|}
\hline & ParkFit & ParkSafe \\
\hline $\begin{array}{l}\text { Intensity } \\
\text { Year } 1\end{array}$ & $\begin{array}{l}\text { Maximum of } 19 \text { physical therapy sessions based on problems and } \\
\text { disabilities as perceived by each individual patient; the systematic } \\
\text { way of } \\
\text { tailoring goals is described in the evidence-based guideline for } \\
\text { physical } \\
\text { therapy in PD } \\
16 \text { coaching sessions to identify and focus on individual beliefs } \\
\text { and aims to } \\
\text { promote a physically active lifestyle }\end{array}$ & $\begin{array}{l}\text { Maximum of } 35 \text { physical therapy sessions based on problems } \\
\text { and } \\
\text { disabilities as perceived by each individual patient; the } \\
\text { systematic way } \\
\text { of tailoring goals is described in the evidence-based } \\
\text { guideline } \\
\text { for physical therapy in PD }\end{array}$ \\
\hline $\begin{array}{l}\text { Intensity } \\
\text { Year } 2\end{array}$ & $\begin{array}{l}\frac{\text { Maximum of } 23 \text { physical therapy sessions based on problems and }}{\text { disabilities as perceived by each individual patient }} \\
\frac{12 \text { coaching sessions to identify and focus on individual beliefs }}{\text { and aims to }} \text { promote a physically active lifestyle }\end{array}$ & $\begin{array}{l}\text { Maximum of } 35 \text { physical therapy sessions } \text { based on problems } \\
\text { disabilities as perceived by each individual patient }\end{array}$ \\
\hline \multirow[t]{5}{*}{$\begin{array}{l}\text { Specific } \\
\text { Elements }\end{array}$} & $\begin{array}{l}\text { ParkFit Brochure: } \\
\text { - Education about benefits of physical therapy } \\
\text { - Identifying aims of physical therapy } \\
\text { - Education about the benefits of physical activity } \\
\text { - Identifying barriers to engage physical activity } \\
\text { - Setting goals } \\
\text { - Recruiting social support } \\
\text { - Sign a health contract to support patients in initiating and } \\
\text { maintaining } \\
\text { physical activities } \\
\text { - A logbook to describe and monitor the specific goals }\end{array}$ & $\begin{array}{l}\text { ParkSafe Brochure: } \\
\text { - Education about benefits of physical therapy } \\
\text { - Identifying aims of physical therapy } \\
\text { - Education about the importance of safety when performing } \\
\text { daily activities }\end{array}$ \\
\hline & $\begin{array}{l}\text { Physical therapist: } \\
\text { who treat the patient in order to obtain the aims of } \\
\text { the individual projected treatment plan } \\
\text { Personal Activity Coach: } \\
\text { who guide patients towards a more active } \\
\text { lifestyle }\end{array}$ & $\begin{array}{l}\text { Physical therapist: } \\
\text { who treat the patient in order to obtain the aims of } \\
\text { the individual projected treatment plan }\end{array}$ \\
\hline & $\begin{array}{l}\text { Goal setting: creating goals to increase the level } \\
\text { of physical activity in order to obtain the half- } \\
\text { year-goals as formulated in the health contract; } \\
\text { goals will be evaluated as well as experienced } \\
\text { barriers and possible solving techniques }\end{array}$ & \\
\hline & $\begin{array}{l}\text { Ambulatory Activity Monitor: gives visual } \\
\text { feedback about the level of physical activity } \\
\text { during the day }\end{array}$ & \\
\hline & $\begin{array}{l}\text { Bi-annual newsletter: specific information about } \\
\text { physical activity, general information about } \\
\text { Parkinson's disease, and general entertainment in } \\
\text { order to facilitate compliance }\end{array}$ & $\begin{array}{l}\text { Bi-annual newsletter: specific information about } \\
\text { physical therapy, general information about } \\
\text { Parkinson's disease, and general entertainment in } \\
\text { order to facilitate compliance }\end{array}$ \\
\hline
\end{tabular}

more active lifestyle, during specific coaching sessions. Their task is to educate patients about the beneficial effects of physical activity. Patients are additionally stimulated to participate in group exercise to experience the beneficial effects of physical activity and to receive social support from fellow patients[26]. For safety reasons, all patients are encouraged to receive a preventive sports medical screening.

3) Goal setting Patient and coach create activity goals in order to obtain the 6-month-goals (as formulated in the health contract). Goals have to be realistic, concrete and individualized and have to be formulated in a systematic way, based on behavioral change theories[25].

4) Ambulatory Activity Monitor with visual feedback Patients receive a personal ambulatory monitor with automated visual feedback showing the amount of actually delivered daily physical activity, recorded by a triaxial accelerometer[27,28]. Additionally, a personalized website shows the activity history[27]. Previous work showed that feedback from pedometers increases physical activity levels in COPD patients[29], sedentary workers[30] and patients with diabetes mellitus[31]. 
5) Physical therapy The ParkFit Program also includes a maximum of 19 physical therapy sessions in year 1 and 23 in year 2. Based on individual disabilities, therapist and patient jointly formulate treatment aims based on the evidence-based guideline of physical therapy for $\mathrm{PD}[32]$.

\section{ParkSafe Program}

The ParkSafe Program includes physical therapy interventions from the physical therapy guideline for $\mathrm{PD}[32]$ to stimulate patients to move more safely, e.g. by improving the quality of transfers, but without explicit emphasis on reaching a physically active lifestyle.

1) Brochure ParkSafe Patients receive a brochure with information about the benefits of physical therapy[32]. Specific emphasis is given to the importance of safety when performing daily activities.

2) Physical therapy Patients receive an individualized physical therapy program. We maximized the total number of sessions at 35/year, to avoid large differences in number of treatment sessions between the two arms (patients in the ParkFit arm also receive 35 annual sessions: 19 physiotherapy plus 16 coach sessions). 35 sessions is considered sufficient for patients in Hoehn and Yahr stage $\leq 3$. Physical therapist and patient jointly formulate the aims of the projected treatment plan, based on individual problems and disabilities. The aims of the physical therapy sessions in both treatment arms are derived from the guideline for physical therapy in PD.

\section{Implementation}

\section{Training for physical therapists}

All participating physical therapists were specifically trained to treat patients in both treatment arms and informed about the aim of the study. Special attention was given to models of behavioral change, $[14,17]$ to specific strategies of coaching sedentary patients,[15,33] and to the technique of setting realistic, concrete and individualized goals[25]. Throughout the trial, therapists continuously register the individual treatment sessions.

\section{Outcome measures}

\section{Baseline characteristics}

Blood pressure, height, body weight, education and employment are assessed at baseline as well as alcohol use, smoking history and lifetime physical activity[34]. Participants in the ParkFit Program also completed a questionnaire about attitude, social support and self-efficacy towards physical activity.

\section{Primary endpoint: level of physical activity}

Primary endpoint is the level of physical activity, as measured with a 7-day recall, based on an interviewbased physical activity questionnaire, the LAPAQ[35]. Patients are asked to list their daily amount of activity (frequency and duration), so total time spent on physical activity (in hours per day) will be calculated. A METvalue will be used to calculate the number of kilocalories spent per day per kilogram of body weight[36]. The LAPAQ is completed during a face-to-face interview (at baseline, 12 and 24 months) and at additional time points by telephone (6 and 18 months). We assume that patients will increase their level of physical activity during the first months of intervention and then maintain this level. Therefore, main endpoint is the level of physical activity during the entire follow-up period (i.e. the mean of $6,12,18$ and 24 months).

\section{Secondary endpoints (Table 2)}

Secondary measures include: (a) physical fitness, measured with the six minute walk test (6MWT)[37]; (b) quality of life, measured with the PDQ-39[38]; and (c) level of physical activity in time and kilocalories per week, measured with the same tri-axial accelerometer that is used as feedback-tool in the ParkFit Program[28]. The level of physical activity is additionally measured with a physical activity diary.

\section{Additional measures}

Patients who increased their amount of physical activity will be compared with patients unable to achieve this, to assess specific health consequences. Disease progression (UPDRS motor section [39]; 9-hole peg board test [40]), mobility (Timed Up and Go test[41]), quality of sleep (SCOPA-sleep[42]), anxiety and depression (HADS[43]), fatigue (Fatigue Severity Scale[44]), and cognitive functioning (Table 2 for test battery) are assessed. Additionally, physical fitness is measured with the Åstrand-Ryhming test[45]. Bone mineral density (dual energy X-ray absorptiometry, DXA) is determined in a subgroup of 300 patients. PD medication and medical costs (combined with the EQ-5D[46]) are assessed, as well as the number of falls (as an index of safety). Patients are asked whether their falls occurred during exercise and about the consequences of falls (e.g. injuries). Information about other adverse events is collected systematically at each physical assessment.

\section{Blinding}

To avoid bias due to more positive expectations of patients towards the outcomes of the ParkFit Program, patients were initially informed about the fact that there are two intervention groups, each with a beneficial intervention. To ensure blinding during assessments, patients are assessed by trained assessors who are unaware of group allocation. Patients are explicitly asked to not share their experiences with the program during the assessments.

\section{Sample size calculation}

Based on the following power considerations, we aimed to include a total of 700 patients. In a small observational study on physical activity in PD, patients scored $45 \%$ less on the LAPAQ compared to controls 
Table 2 An overview of patient assessments

\begin{tabular}{|c|c|c|c|c|c|}
\hline & Baseline & 6 months & 12 months & 18 months & 24 months \\
\hline & $\begin{array}{c}\text { Visit \& } \\
\text { Questionnaires }\end{array}$ & Questionnaires & $\begin{array}{c}\text { Visit \& } \\
\text { Questionnaires }\end{array}$ & Questionnaires & $\begin{array}{c}\text { Visit \& } \\
\text { Questionnaires }\end{array}$ \\
\hline \multicolumn{6}{|l|}{ Physical Activity } \\
\hline$\angle A P A Q$ & $x$ & $x$ & $x$ & $x$ & $x$ \\
\hline Activity Monitor & $x$ & $x$ & $x$ & $x$ & $x$ \\
\hline Activity Diary & $x$ & $x$ & $x$ & $x$ & $x$ \\
\hline \multicolumn{6}{|l|}{ Physical Fitness } \\
\hline $6 \mathrm{MWT}$ & $x$ & & $x$ & & $x$ \\
\hline Åstrand-Ryhming test & $x$ & & $x$ & & $x$ \\
\hline \multicolumn{6}{|l|}{ Quality of Life } \\
\hline PDQ-39 & $x$ & $x$ & $x$ & $x$ & $x$ \\
\hline \multicolumn{6}{|l|}{ Health Effects } \\
\hline UPDRS III, motor function & $x$ & & $x$ & & $x$ \\
\hline Nine hole peg board test & $x$ & & $x$ & & $x$ \\
\hline Timed up and go test & $x$ & & $x$ & & $x$ \\
\hline DXA & $x$ & & & & \\
\hline SCOPA-sleep & $x$ & $x$ & $x$ & $x$ & $x$ \\
\hline HADS & $x$ & $x$ & $x$ & $x$ & $x$ \\
\hline FSS & $x$ & $x$ & $x$ & $x$ & $x$ \\
\hline Cognitive testing battery* & $x$ & & $x$ & & $x$ \\
\hline PD medication & $x$ & $x$ & $x$ & $x$ & $x$ \\
\hline Medical costs \& EQ-5D & $x$ & $x$ & $x$ & $x$ & $x$ \\
\hline Number of falls (monthly) & $x$ & $x$ & $x$ & $x$ & $x$ \\
\hline \multicolumn{6}{|l|}{ Determinants } \\
\hline Blood pressure & $x$ & & $x$ & & $x$ \\
\hline Height & $x$ & & $x$ & & $x$ \\
\hline Body weight & $x$ & & $x$ & & $x$ \\
\hline Education & $x$ & & & & \\
\hline Employment & $x$ & & & & \\
\hline Alcohol use & $x$ & & $x$ & & $x$ \\
\hline Smoking & $x$ & & $x$ & & $x$ \\
\hline Lifetime physical activity & $x$ & & & & \\
\hline Attitude, SS \& SE** & $x$ & & & & \\
\hline
\end{tabular}

* Including tests for spatial working memory[49], intra- and extra-dimensional shift performance[50,51], paired associate learning performance[50], phonemic and semantic word fluency[52], and complex figure drawing[53]

* Only patients in the ParkFit Program

(unpublished data). The coefficient of variation was $110 \%$. Based on a difference of $15 \%$ (with coefficient of variation of $110 \%$ ) between both treatment arms, the study will have at least $80 \%$ power (when the correlation between baseline and follow-up measurements is at least 0.50 and when the correlation between the various follow-up measurements is at most 0.85 ). This is also the power when the correlations are at least 0.60 and at most 0.95 , respectively. The power is based on twosided $95 \%$ confidence intervals. We assumed that patients would take part in exercise groups with on average eight participants and that the corresponding ICC would be 0.1. Based on a previous trial of physical therapy for PD involving the national ParkinsonNet networks[21], we expect a drop-out rate of $10 \%$.

\section{Randomization}

A minimization algorithm is used to randomize patients, with the factors region, Hoehn \& Yahr stage, age, gender and current level of physical activity.

\section{Statistical analyses}

All participants who really started with their program, will be included in the primary analysis. The results after 6, 12, 18 and 24 months will be evaluated using a linear mixed model with random nested factors 'patient' and 'exercise group'. Fixed factors will be treatment arm, LAPAQ score at baseline, month, month"treatment (interaction), and the factors region, H\&Y stage, age, gender and bone density assessment. In an additional analysis, the influence of $H \& Y$ stage, age, gender and level of previous sports activities on the success of the 
treatment will be evaluated by including the interaction terms between treatment and each of these variables in the model. Multiple imputation analyses will be used to evaluate the impact of missing values on the outcome. Throughout, 95\% confidence intervals will be calculated.

\section{Results}

\section{Inclusion procedure}

Selection of patients ran from September 2008 to January 2010. A total number of 4479 patients received a screening questionnaire; 587 (13.1\%) did not respond, 439 (9.8\%) were excluded because there was doubt about the diagnosis (Figure 2). After invitation for participation, 1766 patients were excluded based on our exclusion criteria, and 1101 eligible patients were

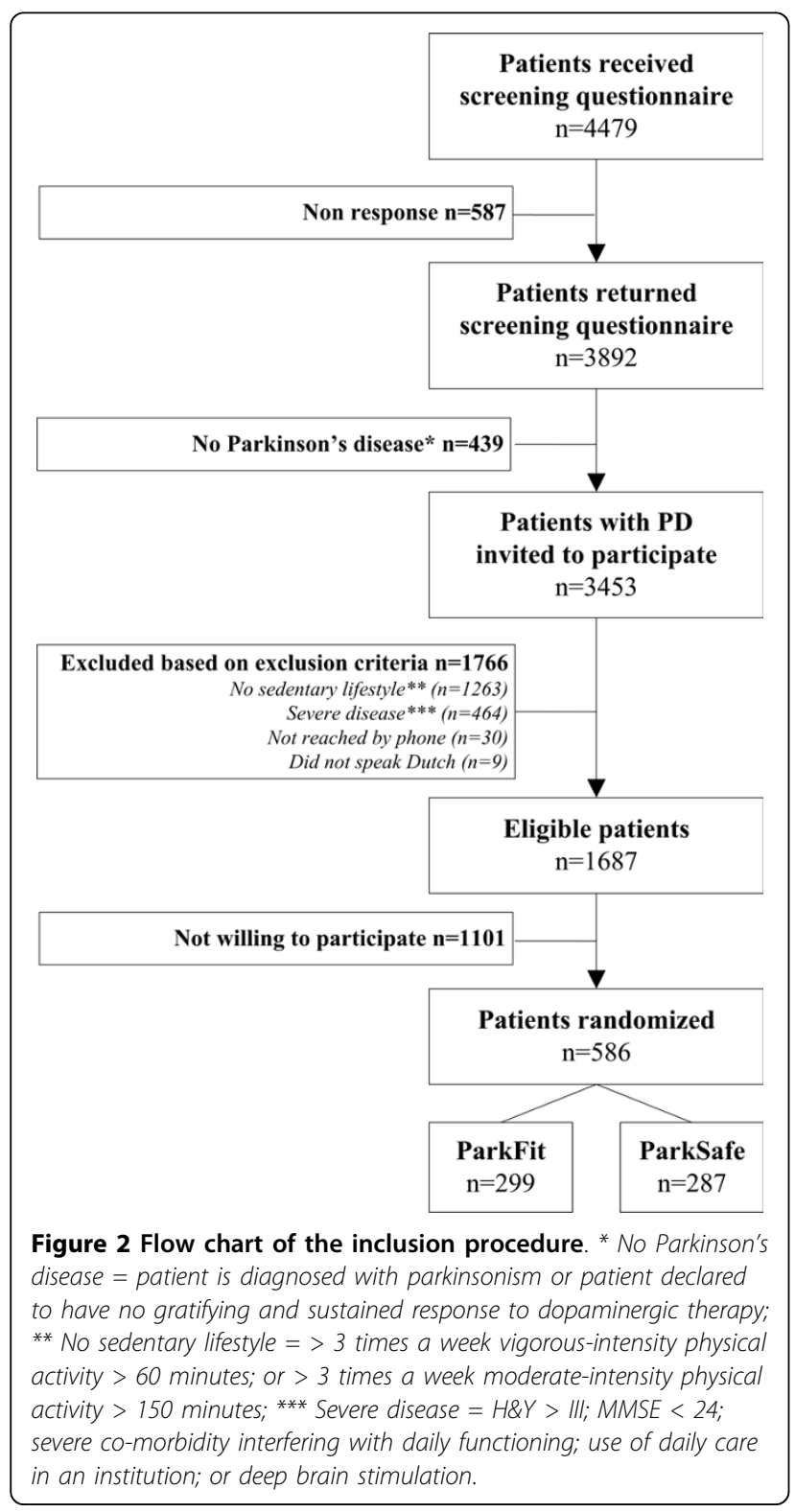

excluded because they were not willing to participate. Finally, 586 patients signed informed consent. The number of enrolled patients is less than the power calculation required. However, the power remains over $80 \%$ because only $60 \%$ of patients participates in exercise groups with an average group size of only three, whereas our power calculation assumed that all patients would participate in exercise in groups of eight patients.

\section{Baseline characteristics}

The most relevant baseline characteristics of included patients are presented in Table 3 and compared with the characteristics of the complete cohort of PD patients and the cohort of patients who were eligible but not willing to participate. Study participants were younger, had a shorter disease duration and were less sedentary compared with eligible patients not willing to participate.

\section{Discussion}

Several lines of evidence suggest that regular participation in physical activity could be important for patients with PD[47]. The ParkFit trial was designed to evaluate a multifaceted program to achieve an enduring increase in physical activity in PD patients. The intervention is based on accepted motivational and behavioral change models[14,16,17], which will now be employed for the first time in PD.

We carefully monitored the characteristics of all invited patients as well as eligible patients who were not willing to participate. The results demonstrate that among all PD patients who were invited, $64 \%$ indeed had a sedentary lifestyle. The results further demonstrate that eligible PD patients not willing to participate were on average somewhat more sedentary in comparison with the participants of the study. Should our study shows a beneficial effect of the ParkFit behavioral change program, efforts must be made to also reach out to this subgroup of sedentary patients.

A critical issue in rehabilitation studies is the choice for an appropriate control condition, and we have selected a program that emphasized safety of movement (according to evidence-based guidelines[32]), rather than the quantity of movements. Both intervention programs are matched for intensity, and are delivered by the same therapists. We have taken several measures to avoid bias between both treatment arms, rendering both groups comparable except for the focus on physical activities. Because the same therapists participate in both programs, differences in their personalities should not differ between the two treatment arms. A possible drawback is contamination. Furthermore, personal preference for a specific program can possibly introduce variation between therapists. We strive to avoid this by: (1) 


\begin{tabular}{lccc}
\hline & $\begin{array}{c}\text { Complete cohort } \\
\text { of PD patients }\end{array}$ & Not willing to participate & Willing to participate \\
\hline $\mathbf{N}$ & & 1101 & 586 \\
Gender (\% male) & 3453 & 53.4 & 65.4 \\
Age (years) & 59.0 & $67.2(7.1)$ & $64.1(7.6)$ \\
Disease duration (years) & $66.1(7.2)$ & $6.0(5.6)$ & $5.3(4.6)$ \\
Ability to walk (\%) & $6.2(5.7)$ & & $157(26.8)$ \\
Normal & & $232(21.3)$ & $348(59.4)$ \\
Slow but independently & $814(23.7)$ & $556(51.0)$ & 81 (13.8) \\
Independently with walking aid & $1747(50.8)$ & $302(27.7)$ & $59.2(71.9)$ \\
With help of someone & $605(17.6)$ & & \\
Wheelchair bounded & $112(3.3)$ & $40.1(61.1)$ & \\
Level of physical activity (min/week) & $158(4.6)$ & & \\
\hline
\end{tabular}

specific training, informing all therapists about the aim of the study and the do's and don'ts in both treatment arms. They have signed a contract and agreed to keep both programs separate. (2) The tools used in ParkFit are not freely available. Since all patients receive their own Activity Monitor and brochure, therapists cannot give these tools to patients allocated to ParkSafe. (3) During the trial, therapists are being visited and observed during one or more sessions. A standardized checklist of prescribed interventions will be completed to investigate if contamination is at play. (4) Each therapist will be interviewed, between 3 to 6 months after start of the program. The aim is to investigate how therapists put the program into practice, and to reemphasize the do's and don'ts of both programs. (5) About every two months, the research team contacts each therapist to ask them about their individual aims in both treatment arms. Again, it is emphasized that coaching towards a more physically active lifestyle is not allowed in ParkSafe. (6) Yearly, a 'booster' session is planned for therapists to discuss possible problems and to re-emphasize the do's and don'ts.

A strong element of the ParkFit trial is the availability of our national ParkinsonNet networks[21], which allows us to administer the interventions in both treatment arms by therapists with documented experience in treating PD patients. The ParkFit trial is one of the largest and longest lifestyle intervention trials in $\mathrm{PD}$, and is the first one to focus on behavioral change as an intermediate to achieve a sustained increase in physical activity levels.

The endpoints of this trial cover several complementary domains. A prerequisite is that patients will actually increase their physical activity levels. To document this, we have selected the time spent on physical activities per week as primary endpoint. We choose the LAPAQ as primary outcome measure instead of the Activity
Monitor because a questionnaire covers a wider range of activities[48].

We also want to see whether physical activity affords any symptomatic relief of PD. To this end we have included a battery of additional endpoints (including quality of life) that measure possible health benefits for patients. Safety is also an issue, because physical activity may theoretically predispose patients to falls. Therefore, this will also be documented in this study. Furthermore, costs will be recorded, although we have no specific a priori reason to expect drastic increases or reductions in costs associated with the interventions of this trial.

In conclusion, the ParkFit trial is expected to yield important new knowledge about behavioral interventions for patients with PD to change their sedentary lifestyle. If the ParkFit Program shows good treatment compliance and beneficial symptomatic effects, future trials could identify which components of our multifaceted approach are most effective. In addition, positive results may have implications for different neurological disorders where beneficial effects of physical activity may be expected. The results of the ParkFit trial are scheduled for 2012 .

\section{Acknowledgements}

This research is supported by grants from ZonMw, The Netherlands Organization for Health Research and Development (75020012), and the Michael J Fox Foundation for Parkinson's research. Furthermore, health insurer VGZ financially supported the ParkFit study. Professor Bastiaan R. Bloem was supported by a NWO VIDI grant (016.076.352).

We would like to thank the local coordinators of the participating general hospitals:

A Winogrodzka (Academisch Ziekenhuis Maastricht); JCM Zijlmans (Amphia Ziekenhuis); GJ Tissingh (Atrium Medisch Centrum); K Keizer (Catharinaziekenhuis); HJMM Lohmann (Deventer Ziekenhuis); R van Koningsveld (Elkerliek Ziekenhuis); AJW Boon (Erasmus Medisch Centrum); E van Wensen and FE Strijks (Gelre Ziekenhuizen); GA van Meer (Groene Hart Ziekenhuis); A Mosch (HagaZiekenhuis); JP ter Bruggen (Jeroen Bosch Ziekenhuis); MF Roesdi (Kennemer Gasthuis); E Berger ('t Lange Land Ziekenhuis and Medisch Centrum Haaglanden); AGGC Korten (Laurentius Ziekenhuis); M Westerink (Maasstad Ziekenhuis); M Aramideh (Medisch Centrum Alkmaar); R 
Rundervoort (Medisch Centrum Haaglanden); FA Rooyer (Orbis Medisch Centrum); DJ Kamphuis (Reinier de Graaf Groep); GJ de Jong (Sint Franciscus Gasthuis); L van Hooff (Franciscus Ziekenhuis); K Lemmen (Slingeland Ziekenhuis); ThJM Breuer (St. Anna Ziekenhuis); JMJ Krul and PM Laboyrie (Tergooiziekenhuizen); FJW Opstelten (VieCuri Medisch Centrum); AMG Sas (Vlietland Ziekenhuis); PJ Nederveen (Westfriesgasthuis), J Lion (Ziekenhuis Bernhoven); and C Jansen (Ziekenhuis Gelderse Vallei) for their participation in the ParkFit study group.

Furthermore, we would like to thank JW Custers and PJ van der Wees (Royal Dutch Society for Physical therapy), SI Detaille and V Peters (Seneca, Expertise Centre for Sport, Work and Health, HAN University of Applied Sciences), MT Hopman (Department of Physiology, Radboud University Nijmegen Medical Centre), MWA Jongert (TNO Netherlands Organization for Applied Scientific Research), YPT Kamsma (University Medical Center Groningen), SHJ Keus (Departments of Physical Therapy and Neurology, Leiden University Medical Centre; Department of Neurology, Donders Institute for Brain, Cognition and Behavior, Radboud University Nijmegen Medical Centre), G Kwakkel (VU University Medical Center), H Leutscher (Disability Sports Netherlands), W Oerlemans (HAN University of Applied Sciences), CJM van Santen (Society of Exercise Therapists Cesar and Mensendieck), NHMJ van Velthoven (Netherlands Olympic Committee * Netherlands Sports Federation), AMJ van de Wert (Netherlands Institute for Sport en Physical Activity), and T Wolff (Parkinson Vereniging) for their participation in the ParkFit advisory board.

\section{Author details}

'Radboud University Nijmegen Medical Centre (RUNMC); Nijmegen Centre for Evidence Based Practice (NCEBP), Department of Neurology, Nijmegen, The Netherlands. ${ }^{2}$ RUNMC; Donders Institute for Brain, Cognition and Behavior; Department of Neurology, Nijmegen, The Netherlands. ${ }^{3}$ RUNMC Departments of Rehabilitation and Allied Health Occupations, Nijmegen, The Netherlands. ${ }^{4}$ HAN University of Applied Sciences; Nijmegen, The Netherlands. ${ }^{5}$ RUNMC; Department of Epidemiology, Biostatistics and HTA, Nijmegen, The Netherlands. ${ }^{6}$ University Medical Center Utrecht; Department of Rehabilitation, Nursing Science and Sport, Utrecht, The Netherlands. ${ }^{7}$ RUNMC; Nijmegen Centre for Evidence Based Practice (NCEBP), Scientific Institute for Quality of Healthcare, Nijmegen, The Netherlands.

\section{Authors' contributions}

MM, BRB and FJGB wrote the grant application and supervised all project staff. MvN, ADS, GFB, FJGB, BRB, MM, and members of the ParkFit study group contributed to the research design. MVN, ADS, KS and MM participated in organization and execution of the research project. GFB was responsible for sample size calculation and statistical analysis. MvN and SO wrote first draft of the manuscript. All authors read and approved the final manuscript.

\section{Competing interests}

The authors declare that they have no competing interests.

Received: 9 July 2010 Accepted: 19 August 2010

Published: 19 August 2010

\section{References}

1. Lees AJ, Hardy J, Revesz T: Parkinson's disease. Lancet 2009, 373:2055-2066.

2. Fertl E, Doppelbauer A, Auff E: Physical activity and sports in patients suffering from Parkinson's disease in comparison with healthy seniors. J Neural Transm Park Dis Dement Sect 1993, 5:157-161.

3. van Nimwegen ML, van Rossum E, Deeg DJ, Bloem BR, Borm GF, van der Horst $M$, et al: The level of physical activity in patients with Parkinson's disease. Parkinsonism Relat Disord 2008, 14:67-68.

4. Warburton DE, Nicol CW, Bredin SS: Health benefits of physical activity: the evidence. CMAJ 2006, 174:801-809.

5. Mora S, Cook N, Buring JE, Ridker PM, Lee IM: Physical activity and reduced risk of cardiovascular events: potential mediating mechanisms. Circulation 2007, 116:2110-2118.

6. Larson EB, Wang L, Bowen JD, McCormick WC, Teri L, Crane P, et al: Exercise is associated with reduced risk for incident dementia among persons 65 years of age and older. Ann Intern Med 2006, 144:73-81.
7. Blumenthal JA, Babyak MA, Moore KA, Craighead WE, Herman S, Khatri P, et al: Effects of exercise training on older patients with major depression. Arch Intern Med 1999, 159:2349-2356.

8. Driver HS, Taylor SR: Exercise and sleep. Sleep Med Rev 2000, 4:387-402.

9. Acree LS, Longfors J, Fjeldstad AS, Fjeldstad C, Schank B, Nickel K, et al: Physical activity is related to quality of life in older adults. Health Qual Life Outcomes 2006, 4:37.

10. Crizzle AM, Newhouse IJ: Is physical exercise beneficial for persons with Parkinson's disease? Clin J Sport Med 2006, 16:422-425.

11. Hirsch MA, Farley BG: Exercise and neuroplasticity in persons living with Parkinson's disease. Eur J Phys Rehabil Med 2009, 45:215-229.

12. Petzinger GM, Walsh JP, Akopian G, Hogg E, Abernathy A, Arevalo P, et al: Effects of treadmill exercise on dopaminergic transmission in the 1methyl-4-phenyl-1,2,3,6-tetrahydropyridine-lesioned mouse model of basal ganglia injury. J Neurosci 2007, 27:5291-5300.

13. Tillerson JL, Caudle WM, Reveron ME, Miller GW: Exercise induces behavioral recovery and attenuates neurochemical deficits in rodent models of Parkinson's disease. Neuroscience 2003, 119:899-911.

14. Bandura A: Health promotion by social cognitive means. Health Educ Behav 2004, 31:143-164.

15. Hillsdon M, Foster C, Thorogood M: Interventions for promoting physical activity. Cochrane Database Syst Rev 2005, CD003180.

16. Brodie DA, Inoue A: Motivational interviewing to promote physical activity for people with chronic heart failure. J Adv Nurs 2005, 50:518-527.

17. Prochaska JO, Velicer WF: The transtheoretical model of health behavior change. Am J Health Promot 1997, 12:38-48.

18. Hospes $G$, Bossenbroek $L$, ten Hacken NH, van HP, de Greef MH: Enhancement of daily physical activity increases physical fitness of outclinic COPD patients: results of an exercise counseling program. Patient Educ Couns 2009, 75:274-278.

19. Gelb DJ, Oliver E, Gilman S: Diagnostic criteria for Parkinson disease. Arch Neurol 1999, 56:33-39.

20. Nelson ME, Rejeski WJ, Blair SN, Duncan PW, Judge JO, King AC, et al: Physical activity and public health in older adults: recommendation from the American College of Sports Medicine and the American Heart Association. Med Sci Sports Exerc 2007, 39:1435-1445.

21. Munneke M, Nijkrake MJ, Keus SH, Kwakkel G, Berendse HW, Roos RA, et al: Efficacy of community-based physiotherapy networks for patients with Parkinson's disease: a cluster-randomised trial. Lancet Neurol 2010, 9:46-54.

22. Nijkrake MJ, Keus SH, Overeem S, Oostendorp RA, Vlieland TP, Mulleners W, et al: The ParkinsonNet concept: development, implementation and initial experience. Mov Disord 2010, 25:823-829.

23. Nied RJ, Franklin B: Promoting and prescribing exercise for the elderly. Am Fam Physician 2002, 65:419-426.

24. Schutzer KA, Graves BS: Barriers and motivations to exercise in older adults. Prev Med 2004, 39:1056-1061.

25. Haber D, Rhodes D: Health contract with sedentary older adults. Gerontologist 2004, 44:827-835.

26. Resnick B, Nigg C: Testing a theoretical model of exercise behavior for older adults. Nurs Res 2003, 52:80-88.

27. 2010 [http://www.directlife.philips.com], DirectLife triaxial accelerometer for movement registration (TracmorD) (Philips New Wellness Solutions, Lifestyle Incubator, the Netherlands).

28. Bonomi AG, Plasqui G, Goris AH, Westerterp KR: Estimation of Free-Living Energy Expenditure Using a Novel Activity Monitor Designed to Minimize Obtrusiveness. Obesity (Silver Spring) 2010.

29. de Blok BM, de Greef MH, ten Hacken NH, Sprenger SR, Postema K, Wempe JB: The effects of a lifestyle physical activity counseling program with feedback of a pedometer during pulmonary rehabilitation in patients with COPD: a pilot study. Patient Educ Couns 2006, 61:48-55

30. Chan CB, Ryan DA, Tudor-Locke C: Health benefits of a pedometer-based physical activity intervention in sedentary workers. Prev Med 2004, 39:1215-1222.

31. Araiza P, Hewes H, Gashetewa C, Vella CA, Burge MR: Efficacy of a pedometer-based physical activity program on parameters of diabetes control in type 2 diabetes mellitus. Metabolism 2006, 55:1382-1387.

32. Keus SH, Bloem BR, Hendriks EJ, Bredero-Cohen AB, Munneke M: Evidencebased analysis of physical therapy in Parkinson's disease with recommendations for practice and research. Mov Disord 2007, 22:451-460. 
33. de JJ, Lemmink KA, King AC, Huisman M, Stevens M: Twelve-month effects of the Groningen active living model (GALM) on physical activity, health and fitness outcomes in sedentary and underactive older adults aged 55-65. Patient Educ Couns 2007, 66:167-176.

34. Friedenreich CM, Courneya KS, Bryant HE: The lifetime total physical activity questionnaire: development and reliability. Med Sci Sports Exerc 1998, 30:266-274.

35. Stel VS, Smit JH, Pluijm SM, Visser M, Deeg DJ, Lips P: Comparison of the LASA Physical Activity Questionnaire with a 7-day diary and pedometer. J Clin Epidemiol 2004, 57:252-258.

36. Ainsworth BE, Haskell WL, Whitt MC, Irwin ML, Swartz AM, Strath SJ, et al: Compendium of physical activities: an update of activity codes and MET intensities. Med Sci Sports Exerc 2000, 32:S498-S504.

37. Enright $P L$, McBurnie MA, Bittner $V$, Tracy RP, McNamara R, Arnold A, et al: The 6-min walk test: a quick measure of functional status in elderly adults. Chest 2003, 123:387-398.

38. Peto $V$, Jenkinson $C$, Fitzpatrick R: Determining minimally important differences for the PDQ-39 Parkinson's disease questionnaire. Age Ageing 2001, 30:299-302.

39. The Unified Parkinson's Disease Rating Scale (UPDRS): status and recommendations. Mov Disord 2003, 18:738-750.

40. Wade DT: Measurement in neurological rehabilitation. Oxford: Oxford University Press 1992.

41. Morris S, Morris ME, lansek R: Reliability of measurements obtained with the Timed "Up \& Go" test in people with Parkinson disease. Phys Ther 2001, 81:810-818.

42. Marinus J, Visser M, van Hilten JJ, Lammers GJ, Stiggelbout AM: Assessment of sleep and sleepiness in Parkinson disease. Sleep 2003, 26:1049-1054.

43. Mondolo F, Jahanshahi M, Grana A, Biasutti E, Cacciatori E, Di BP: The validity of the hospital anxiety and depression scale and the geriatric depression scale in Parkinson's disease. Behav Neurol 2006, 17:109-115.

44. Grace J, Mendelsohn A, Friedman JH: A comparison of fatigue measures in Parkinson's disease. Parkinsonism Relat Disord 2007, 13:443-445.

45. Siconolfi SF, Cullinane EM, Carleton RA, Thompson PD: Assessing VO2max in epidemiologic studies: modification of the Astrand-Rhyming test. Med Sci Sports Exerc 1982, 14:335-338.

46. EuroQol-a new facility for the measurement of health-related quality of life. The EuroQol Group. Health Policy 1990, 16:199-208.

47. Goodwin VA, Richards SH, Taylor RS, Taylor AH, Campbell JL: The effectiveness of exercise interventions for people with Parkinson's disease: a systematic review and meta-analysis. Mov Disord 2008, 23:631-640.

48. Welk GJ: Physical Activity Assessments for Health-Related Research. Human Kinetics Publishers Inc 2002.

49. Owen AM, Downes JJ, Sahakian BJ, Polkey CE, Robbins TW: Planning and spatial working memory following frontal lobe lesions in man. Neuropsychologia 1990, 28:1021-1034.

50. Owen AM, James M, Leigh PN, Summers BA, Marsden CD, Quinn NP, et al: Fronto-striatal cognitive deficits at different stages of Parkinson's disease. Brain 1992, 115(Pt 6):1727-1751.

51. Downes JJ, Roberts AC, Sahakian BJ, Evenden JL, Morris RG, Robbins TW: Impaired extra-dimensional shift performance in medicated and unmedicated Parkinson's disease: evidence for a specific attentional dysfunction. Neuropsychologia 1989, 27:1329-1343.

52. Schmand B, Groenink SC, van den DM: [Letter fluency: psychometric properties and Dutch normative data]. Tijdschr Gerontol Geriatr 2008, 39:64-76.

53. Rey A: Psychological examination of traumatic encephalopathy [originally published in Archives de Psychologie 1941;28: 286-340; Translated by Corwin J, Bylsma F.]. Clin Neuropsychol 1993, 7:4-9.

\section{Pre-publication history}

The pre-publication history for this paper can be accessed here: http://www.biomedcentral.com/1471-2377/10/70/prepub

doi:10.1186/1471-2377-10-70

Cite this article as: van Nimwegen et al:: Design and baseline characteristics of the ParkFit study, a randomized controlled trial evaluating the effectiveness of a multifaceted behavioral program to increase physical activity in Parkinson patients. BMC Neurology 2010 $10: 70$.

\section{Submit your next manuscript to BioMed Central and take full advantage of:}

- Convenient online submission

- Thorough peer review

- No space constraints or color figure charges

- Immediate publication on acceptance

- Inclusion in PubMed, CAS, Scopus and Google Scholar

- Research which is freely available for redistribution 